\title{
Tumour necrosis factor- $\alpha$ gene promoter polymorphism in chronic obstructive pulmonary disease
}

\author{
M.A. Higham*, N.B. Pride**, A. Alikhan*, N.W. Morrell*
}

Tumour necrosis factor-a gene promoter polymorphism in chronic obstructive pulmonary disease. M.A. Higham, N.B. Pride, A. Alikhan, N.W. Morrell. (C) ERS Journals Ltd 2000. ABSTRACT: Tumour necrosis factor(TNF)- $\alpha$ levels are elevated in airways of patients with chronic obstructive pulmonary disease (COPD) and may contribute to its pathogenesis. A guanine to adenine substitution at position -308 of the TNF- $\alpha$ gene promoter (TNF1/2) has been associated with chronic bronchitis of various aetiologies in a Taiwanese population. The authors performed a study investigating association of the polymorphism with smoking-related COPD in Caucasians.

Frequencies of TNF1/2 alleles in 86 Caucasians (52 males) with COPD were compared with 63 (52 males) asymptomatic smoker/exsmoker control subjects and a population control of 199 (99 males) blood donors. Genotyping was performed by the polymerase chain reaction-restriction fragment length polymorphism technique on genomic deoxyribonucleic acid (DNA) obtained from peripheral blood.

There were no significant differences in TNF1/2 allele frequencies between groups: 0.85/0.15 in COPD, $0.85 / 0.15$ in smoker control subjects, $0.83 / 0.17$ in population control subjects. Within the COPD group there was no association of TNF1/2 alleles with indices of airflow obstruction (\% predicted forced expiratory volume in one second (FEV1) and \% predicted FEV1/vital capacity ratio) nor gas transfer (\% predicted carbon monoxide transfer coefficient and \% predicted carbon monoxide diffusing capacity of the lung).

It is concluded that: 1) the tumour necrosis factor gene promoter allele does not influence the risk of developing chronic obstructive pulmonary disease in a Caucasian population of smokers; and 2) there is no association of the tumour necrosis factor gene promoter genotype with severity of airflow obstruction nor degree of emphysema in chronic obstructive pulmonary disease.

Eur Respir J 2000; 15: 281-284.

Cigarette smoking is the most common preventable cause of chronic obstructive pulmonary disease (COPD). Nevertheless, only $15-20 \%$ of smokers develop the severe impairment of pulmonary function associated with COPD [1] and factors determining susceptibility and disease progression are poorly understood. However, contributions by genetic factors have been implicated [2]. Although the precise nature of the genetic influence remains undefined, studies suggest that inflammation of small and large airways and airspaces as a response to direct exposure to inhaled insults is important in the pathogenesis of COPD [3].

Tumour necrosis factor (TNF)- $\alpha$ is a multifunctional cytokine. In addition to pro-inflammatory properties, there is evidence that TNF- $\alpha$ can promote tracheal smooth muscle proliferation [4] and alter smooth muscle function [5]. Elevated levels are found in bronchoalveolar lavage fluid [6], bronchial biopsies [7] and induced sputum [8] from patients with chronic bronchitis/COPD, suggesting that TNF- $\alpha$ may contribute to the airway remodelling and altered smooth muscle cell function (i.e. airway hyperresponsiveness) found in COPD.

A polymorphism resulting in a guanine to adenine substitution at position -308 of the TNF- $\alpha$ gene promoter (designated TNF1/2) has been described. The rarer allele,
*Clinical Pharmacology and **Respiratory Medicine, Imperial College School of Medicine, Hammersmith Hospital, London, UK.

Correspondence: N.W. Morrell, Section on Clinical Pharmacology, Imperial College School of Medicine, Hammersmith Hospital, Du Cane Road, London, W12 0NN, UK. Fax: 442087439733

Keywords: Chronic obstructive pulmonary disease gene promoter polymorphism tumour necrosis factor- $\alpha$

Received: August 121999

Accepted after revision November 111999

This work was partly supported by grantin-aid generously provided by Glaxo Wellcome Ltd. N.W. Morrell is a Clinician Scientist Fellow of the Medical Research Council (UK).
TNF2, has been associated with higher baseline and induced expression of TNF- $\alpha[9,10]$. Several studies have demonstrated positive associations with the presence of the TNF2 allele and susceptibility to a number of inflammatory diseases, and recently an association between the TNF2 allele and risk of development of chronic bronchitis was reported in a male Taiwanese population [11]. However, the aetiology of airflow obstruction was not clear in the latter study, since $30 \%$ of their patients had never smoked. The aims of the present study were to determine whether the TNF1/2 polymorphism is associated with smoking-related COPD in a Caucasian population and whether the TNF1/2 genotype correlates with disease severity.

Subjects and methods

\section{Subjects}

The study was approved by the Research Ethics Committee of Imperial College School of Medicine, Hammersmith, Queen Charlotte's \& Chelsea and Acton Hospitals, London, UK and all subjects gave written informed consent. 
The patient group consisted of smokers and exsmokers recruited from the Respiratory Outpatient Department at the Hammersmith Hospital, London, UK. All had irreversible chronic airflow limitation and a diagnosis of COPD made according to British Thoracic Society guidelines [12]. No patients with a history of asthma were included. Specific enrolment criteria were: 1) a smoking history of at least 10 pack-years; and 2) forced expiratory volume in one second $(\mathrm{FEV} 1) /$ vital capacity $(\mathrm{VC})$ ratio $\leq 80 \%$ predicted without significant reversibility $(\leq 15 \%$ baseline or $200 \mathrm{~mL}$ ) to $2.5 \mathrm{mg}$ nebulized salbutamol.

Two control groups were used in the study: 1) a smoker control group of smokers and exsmokers with a smoking history of at least 10 pack-years but without evidence of COPD or asthma; and 2) a population control group of anonymous adult Caucasian blood donors from the West London (UK) area.

\section{Pulmonary function tests}

Pulmonary function tests were performed by experienced specialist lung function technicians. Spirometric measurements were made using a dry wedge bellows spirometer (Vitalograph Ltd, Buckingham, Buckinghamshire, UK). Single breath gas transfer measurements were made using a Morgan Benchmark system (Morgan, Rainham, Kent, UK). Reference values were calculated according to the European Respiratory Society's statement on standardized lung function testing [13].

\section{Genotyping protocol}

Three millilitres of whole peripheral blood was obtained from each study participant by phlebotomy of an antecubital vein. Samples were anticoagulated with ethylene diamine tetra-acetic acid (EDTA) and stored at $-20^{\circ} \mathrm{C}$ until required for deoxyribonucleic acid (DNA) extraction. Genomic DNA was extracted from samples using a Nucleon BACC3 kit (Nucleon Biosciences, Coatbridge, UK). Primers 5'AGGCAATAGGTTTTGAGGGCCAT-3' and 5'TCCTCCCTGCTCCGATTCCG-3' were employed to amplify a 107 base pair (bp) fragment containing the variable -308 nucleotide of the human TNF- $\alpha$ promoter. The sense primer was modified to incorporate the polymorphic site into an NcoI restriction site, as previously described by other workers [14]. One hundred nanograms of genomic DNA was amplified with $1 \mathrm{U}$ Pro-zyme DNA polymerase (Bioline Ltd, London, UK) in $25 \mu \mathrm{L}$ of 70 $\mathrm{mM}$ tris-hydroxymethyl-amino methane (Tris)- $\mathrm{HCl}$ containing $20 \mathrm{mM} \mathrm{KCl}, 2 \mathrm{mM} \mathrm{MgCl} 2,200 \mu \mathrm{M}$ of each deoxyribonucleoside triphosphate (dNTP), and $50 \mathrm{pmol}$ of each primer. Amplification was for 35 cycles with denaturation at $94^{\circ} \mathrm{C}$ for $1 \mathrm{~min}$, annealing at $60^{\circ} \mathrm{C}$ for $1 \mathrm{~min}$, and extension at $72^{\circ} \mathrm{C}$ for $1 \mathrm{~min}$. Ten microlitres of the product was digested with $5 \mathrm{U} N \mathrm{NoI}$ (New England Biolabs, Hitchin, Hertfordshire, UK) for $4 \mathrm{~h}$, subjected to electrophoresis in $3.5 \%$ agarose (NuSieve 3:1; FMC Bioproducts, Rockland, ME, USA), and stained with ethidium bromide. The TNF1 allele gives two fragments of $87 \mathrm{bp}$ and $20 \mathrm{bp}$, and the TNF2 allele a single $107 \mathrm{bp}$ fragment. Therefore a homozygote for the TNF1 allele (TNF1/1) gives two bands, whereas a homozygote for the TNF2 allele (TNF2/2) gives one band, and the heterozygote (TNF1/2) gives three bands.

\section{Power statement and data analysis}

The study had an $80 \%$ power at a significance level of $\mathrm{p}=0.05$ to detect an increase in TNF2 allele frequency of 0.13 in the COPD patient group compared to the general population control group.

Age, smoking history and pulmonary function parameters were compared using the Mann-Whitney U-test. Allele and genotype distribution in the patient and control groups were compared using contingency tables, with the Fisher exact test where appropriate. Single factor analysis of variance using the Kruskal-Wallis test was employed to examine whether TNF genotype affected indices of airflow limitation or gas transfer in patients with COPD.

\section{Results}

Fifty-two males and 34 females were recruited to the COPD patient group. The smoker control group consisted of 52 males and 11 females. The population control group was composed of 199 (99 males, 100 females) anonymous blood donors aged 18-65 yrs. Smoking history of the population control subjects was unknown. Age, smoking history and pulmonary function data of COPD patients and smoker control subjects are summarised in table 1 . There was no significant difference in ages between groups. However, the control group, although heavy smokers, were significantly less exposed to tobacco than the COPD group $(\mathrm{p}<0.0001)$. As expected, COPD patients demonstrated significant reductions in \% predicted FEV1 $(\mathrm{p}<$ $0.0001)$ and $\%$ predicted $\mathrm{FEV} 1 / \mathrm{VC}$ ratio $(\mathrm{p}<0.0001)$.

Genotype and allele frequencies of patients versus control subjects are presented in table 2 . There were no significant differences in the distribution of genotype or allele frequencies in these groups.

The following data pertain to the COPD patient group and are presented as mean \pm SEM $\%$ predicted for each variable according to genotype: FEV1: TNF1/1 45.0 \pm 2.4 , $\mathrm{TNF} 1 / 248.8 \pm 4.9, \mathrm{TNF} 2 / 2 \quad 65.4 \pm 2.4 \%$; FEV1/VC ratio: TNF1/1 54.3 \pm 2.0 , TNF1/2 57.8 \pm 3.5 , TNF2/2 58.3 \pm 6.3 ;

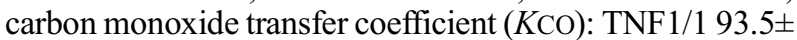
5.4, TNF1/2 85.9 $\pm 11.1, \mathrm{TNF} 2 / 2115 \%$. TNF2/2; carbon monoxide diffusing capacity of the lung ( $D \mathrm{~L}, \mathrm{CO})$ : TNF1/1

Table 1. - Demographics of chronic obstructive pulmonary disease (COPD) and smoker control groups

\begin{tabular}{lccccccc}
\hline & $\begin{array}{c}\text { Age } \\
\text { yrs }\end{array}$ & $\begin{array}{c}\text { Smoking } \\
\text { history } \\
\text { (pack-years) }\end{array}$ & $\begin{array}{c}\text { FEV1 } \\
\text { \% pred }\end{array}$ & $\begin{array}{c}\text { VC } \\
\% \text { pred }\end{array}$ & $\begin{array}{c}\text { FEV1/VC } \\
\text { \% pred }\end{array}$ & $\begin{array}{c}\text { KCO } \\
\% \text { pred }\end{array}$ & $\begin{array}{c}D \text { L,CO } \\
\% \text { pred }\end{array}$ \\
\hline COPD patients n=86 & $67.4 \pm 0.8$ & $51.5 \pm 2.9^{*}$ & $46.5 \pm 2.2$ & $82.8 \pm 2.6$ & $55.3 \pm 1.7$ & $92.0 \pm 4.8^{* *}$ & $75.1 \pm 4.3^{* *}$ \\
Smoker control subjects n=63 & $64.4 \pm 1.3$ & $35.7 \pm 2.6^{+}$ & $93.5 \pm 2.4$ & $98.6 \pm 2.1$ & $92.6 \pm 0.9$ & $118.6 \pm 3.2^{++}$ & $108.8 \pm 3.5^{++}$ \\
\hline
\end{tabular}

Mean values \pm SEM are shown. *: full history available for 67 patients; **: data available for 57 patients; ${ }^{+}$: full history available for 59 patients; ${ }^{++}$: data available for 60 subjects. 
Table 2. - Distributions of tumour necrosis factor (TNF)- $\alpha$ genotypes and allele frequencies in chronic obstructive pulmonary disease (COPD) patients and control subjects

\begin{tabular}{lcccccc}
\hline & \multicolumn{3}{c}{$\begin{array}{c}\text { Genotype frequency } \\
\text { (number of individuals) }\end{array}$} & & \multicolumn{2}{c}{$\begin{array}{c}\text { Allele frequency } \\
\text { (number of alleles) }\end{array}$} \\
\cline { 2 - 6 } & TNF1/1 & TNF1/2 & TNF2/2 & & TNF1 & TNF2 \\
\hline COPD patients & 0.72 & 0.26 & 0.02 & & 0.85 & 0.15 \\
n=86 & $(62)$ & $(22)$ & $(2)$ & & $(146)$ & $(26)$ \\
Smoker control subjects & 0.71 & 0.27 & 0.02 & $(1)$ & 0.85 & 0.15 \\
n=63 & $(45)$ & $(17)$ & 0.03 & $(107)$ & 0.83 & 0.17 \\
Population control subjects & 0.68 & 0.29 & $(6)$ & $(329)$ & $(69)$ \\
n=199 & $(136)$ & $(57)$ & & & \\
\hline
\end{tabular}

No significant differences between groups (contingency tables).

$77.4 \pm 4.8, \mathrm{TNF} 1 / 2 \quad 65.4 \pm 9.2, \mathrm{TNF} 2 / 2 \quad 110 \%$. Analysis of variance did not reveal effects of genotype on severity of airflow obstruction nor defects in gas transfer.

\section{Discussion}

This study compared the frequency of a common biallelic polymorphism in the promoter region of the TNF- $\alpha$ gene (designated TNF1/2) in Caucasian patients with smoking-related COPD and an age-matched control group of smokers and exsmokers. The results indicate that there is no association of TNF1/2 alleles with susceptibility to smoking-related COPD. Furthermore, there appears to be no association of TNF $1 / 2$ genotype with severity of COPD nor a relation to degree of emphysema.

It should be noted that the smoker control group were significantly less exposed to tobacco than the disease group, and this could be a cause of the groups' differing susceptibilities to COPD. However, there is known to be a wide variation in annual rate of decline in FEV1 in smokers with similar cigarette consumption and that characterization of smoking habit in terms of cumulative pack-years ignores other complicating risk factors such as depth of inhalation and chemical yield of cigarettes 115]. It is therefore believed that the smoker control group recruited to the present study were a representative sample of the $80-85 \%$ of smokers who are resistant to developing COPD [1].

The results are at odds with a smaller study by HuANG et al. [11], who reported that carriage of the TNF2 allele was associated with chronic bronchitis in a Taiwanese population, with an odds ratio of 11 . There are, however, a number of differences between the study by HUANG et al. [11] and the present study. First, the aetiology of airflow limitation in the Taiwanese study was not necessarily related to cigarette consumption. Approximately one third of their chronic bronchitis patients were nonsmokers, and it is likely that other factors which occur in Japan and Southeast Asia may have contributed, such as diffuse panbronchiolitis. Second, the frequency of the TNF2 allele was much lower in their general population control than in the present study: $5 \%$ versus $17 \%$. This may represent a true ethnic difference in the frequency of the TNF2 allele, since the frequencies in the present control groups are similar to those found by other workers studying predominantly Caucasian populations [16, 17]. However, other workers studying Chinese populations have found TNF2 allele frequencies of $9-14 \%$ in control populations [18, 19].
A number of studies have sought associations between the TNF2 allele and disease manifestation, since this rarer allele is reputedly associated with higher baseline and inducible TNF- $\alpha$ expression in transfection studies [9]. However, it is debated whether this effect is observed in vivo. For example, one large study reported no effect of TNF $1 / 2$ genotype on circulating TNF- $\alpha$ or its soluble receptors [16]. Despite this, associations have been reported between the TNF2 allele and rheumatoid arthritis [20], and risk of death from cerebral malaria [21]. There may also be an association with systemic lupus erythematosus in some races but not others, although this is debated $[17,18]$. The underlying molecular basis of these reported associations remain to be fully elucidated.

Association studies, such as the current study, cannot be used to suggest that TNF- $\alpha$ is not a key mediator in smoking-related airway inflammation and remodelling, since the pathogenesis of airway disease is complex and especially considering the uncertainty regarding the relationship between the TNF1/2 polymorphism and TNF- $\alpha$ expression in vivo. Also, it may be that another TNF promoter polymorphism is of greater functional significance in COPD than the TNF $1 / 2$ polymorphism, which may not be in linkage disequilibrium with the relevant polymorphism. Further genetic investigation of TNF- $\alpha$ and COPD may therefore be worthwhile.

In summary, the data does not implicate the tumour necrosis factor- $\alpha 1 / 2$ gene promoter polymorphism as a risk factor for the susceptibility to nor severity of chronic obstructive pulmonary disease in Caucasian smokers, although tumour necrosis factor- $\alpha$ may still have a central role in the process of airway inflammation in smokingrelated airways disease.

Acknowledgements. The authors thank the UK National Blood Transfusion Service for kindly providing population control blood samples. The authors also thank A. Watson for technical expertise in performing this study.

\section{References}

1. Snider GL. Defining chronic obstructive pulmonary disease. In: Calverley P, Pride N, eds. Chronic Obstructive Pulmonary Disease. London, UK, Chapman \& Hall, 1995; 1-8.

2. Redline S, Tishler PV, Lewitter FI, Tager IB, Munoz A, Speizer FE. Assessment of genetic and nongenetic influences on pulmonary function. Am Rev Respir Dis 1987; 135: 217-222. 
3. Saetta M, Stefano AD, Maestrelli P, et al. Activated Tlymphocytes and macrophages in bronchial mucosa of subjects with chronic bronchitis. Am Rev Respir Dis 1993; 147: 301-306.

4. Amrani Y, Panettieri RA, Frossard N, Bronner C. Activation of the TNF $\alpha$-p55 receptor induces myocyte proliferation and modulates agonist-evoked calcium transients in cultured human tracheal smooth muscle cells. $\mathrm{Am} \mathrm{J}$ Respir Cell Mol Biol 1996; 15: 55-63.

5. Emala CW, Kuhl J, Hungerford CL, Hirshman CA. TNFalpha inhibits isoproterenol-stimulated adenylyl cyclase activity in cultured airway smooth muscle cells. $A m J$ Physiol 1997; 272: L644-L650.

6. Sun G, Stacey MA, Vittori E, et al. Cellular and molecular characteristics of inflammation in chronic bronchitis. Eur J Clin Invest 1998; 28: 364-372.

7. Mueller R, Chanez P, Campbell AM, Bousquet J, Heusser C, Bullock GR. Different cytokine patterns in bronchial biopsies in asthma and chronic bronchitis. Respir Med 1996; 90: 79-85.

8. Keatings VM, Collins PD, Scott DM, Barnes PJ. Differences in interleukin- 8 and tumor necrosis factor- $\alpha$ in induced sputum from patients with chronic obstructive pulmonary disease or asthma. Am J Respir Crit Care Med 1996; 153: 530-534.

9. Kroeger KM, Carville KS, Abraham LJ. The -308 tumor necrosis factor-alpha promoter polymorphism effects transcription. Mol Immunol 1997; 34: 391-399.

10. Wilson AG, Symons JA, McDowell TL, McDevitt HO, Duff GW. Effects of a polymorphism in the human tumor necrosis factor alpha promoter on transcriptional activation. Proc Natl Acad Sci USA 1997; 94: 3195-3199.

11. Huang S-L, Su C-H, Chang S-C. Tumor necrosis factor- $\alpha$ gene polymorphism in chronic bronchitis. Am J Respir Crit Care Med 1997; 156: 1436-1439.

12. British Thoracic Society. BTS guidelines for the manage- ment of chronic obstructive pulmonary disease. Diagnosis and management of stable COPD. Thorax 1997; 52 (Suppl. 5): S7-S15.

13. European Respiratory Society. Standardized lung function testing. Eur Respir J 1993; 6 (Suppl. 6): 1-100.

14. Wilson AG, di Giovane FS, Blakemore AIF, Duff GW. Single base polymorphism in the human tumour necrosis factor alpha (TNF $\alpha)$ gene detectable by NcoI restriction of PCR product. Hum Mol Genet 1992; 1: 353.

15. Pride NB, Burrows B. Development of impaired lung function: natural history and risk factors. In: Calverley P, Pride NB, eds. Chronic Obstructive Pulmonary Disease. London, UK, Chapman \& Hall, 1995; pp. 69-91.

16. Kubota T, McNamara D, Wang JJ, et al. Effects of tumor necrosis factor gene polymorphisms on patients with congestive heart failure. Circulation 1998; 97: 2499-2501.

17. Rudwaleit M, Tikly M, Khamashata M, et al. Interethnic differences in the association of tumor necrosis factor promoter polymorphisms with systemic lupus erythematosus. J Rheumatol 1996; 23: 1725-1728.

18. Chen CJ, Yen JH, Tsai WC, et al. The TNF2 allele does not contribute towards susceptibility to systemic lupus erythematosus. Immunol Lett 1997; 55: 1-3.

19. Fong KY, Howe HS, Tin SK, Boey ML, Feng PH. Polymorphism of the regulatory region of tumour necrosis factor alpha gene in patients with systemic lupus erythematosus. Ann Acad Med Singapore 1996; 25: 90-93.

20. Danis VA, Millington M, Hyland V, Lawford R, Huang $\mathrm{Q}$, Greenan D. Increased frequency of the uncommon allele of a tumour necrosis factor alpha gene polymorphism in rheumatoid arthritis and systemic lupus erythematosus. Dis Markers 1995; 12: 127-133.

21. McGuire W, Hill AVS, Allsopp CEM, Greenwood BM, Kwjatkowski D. Variation in the TNF- $\alpha$ promoter region associated with susceptibility to cerebral malaria. Nature 1994; 371: 508-511. 